\title{
O CONTO ESPANHOL CONTEMPORÂNEO: FRAGMENTOS DA HISTÓRIA
}

\author{
Valeria De Marco
}

Depto. de Letras Modernas Universidad de São Paulo

Para nós, leitores brasileiros, o conto é elemento constitutivo fundamental de nossa experiência literária. Desde Machado de Assis, o gênero deleita e chama a atenção de críticos e historiadores da literatura. Se ampliammos um pouco nosso horizonte para as relações de vizinhança e parentesco, deparamos com a enorme, variada e riquísima produção do conto hispano-americano. Para o estudioso das humanidades é impossível conhecer o mundo cá abaixo do Equador sem mergulhar neste continente de contos.

Ao começarmos estudar a Literatura Espanhola, esta é nossa experiência de vida. Acostumados às short-stories, procuramos o conto espanhol e esbarramos con enormes dificuldades para encontrá-lo, pois a intensa e extensa produção de contos na Espanha de pós-guerra não suscitou a curiosidade dos críticos e, apenas no fim da década de 70, despetou interesse das grandes editoras, talvez motivadas pelo mercado aberto em terras da ex-metrópole pelo conto hispanoamericano. Mas nas histórias literárias, mesmo naquelas da década de 80 , o conto não tem vez. Elas dedicam algum espaço à fundação nobre do gênero na Idade Média: Don Juan Manuel e seu livro El Conde Lucanor. Depois o conto aparece sempre como mera referência, como uma entre tantas atividades intelectuais exercidas por tal ou qual narrador. Por isso, pelas histórias literárias não podemos sequer dimensionar a mudança quantitativa e qualitativa na produção de contos na Espanha a partir de 1940. Esse tipo de tratamento dispensado ao conto pelos críticos poderia ser atribuído, num primeiro momento, ao fato de não encontrarmos na Espanha contistas do porte de Borges ou Guimarães Rosa. Mas a ques-

Texto apresentado no I CONGRESSO BRASILEIRO DE PROFESSORES DE ESPANHOL realizado no Rio de Janeiro de 16 a 18 de outubro de 1985. 
tão não está aí. O problema está em compreender o gênero e sobretudo encará-lo como objeto legítimo da reflexão do crítico. O conto não deve ser visto como gênero menor ou como primeiro exercício de aprendizado para o romancista. Estes preconceitos aparecem em muitos cantos, mas na Espanha encontram solo especialmente fértil, pois o país tem uma longa história de formação de mentalidade calcada na pretensão imperial de Castela, na utopia de unidade e totalidade, no desejo da grande épica. Certamente, esse é um entrave para pensar o conto como género, pois este é o lugar da pequena história, do mundo do fragmento, do desgarramento absoluto dos «tempos modernos», da vida no varejo, do contínuo cotidiano.

Estas considerações levam-me a formular uma hipótese de trabalho. Não veriam os narradores no conto, essa forma multifacetada e fragmentária, um modo de aproximação e interpretação, uma forma de expressão do homem contemporâneo dilacerado? Dilacerado pela velocidade, pela guerra, pela nova sensibilidade de tempo e espaço, pela absoluta mecanização do trabalho, pelo consumo das imagens do cinema, da informação e da propaganda. Essas experiências não engendrariam outras maneiras de contar histórias e não pediriam outro jeito de escrever a História? Lembro aqui duas frases de Walter Benjamin: "O homen de hoje não trabalha naquilo que não pode ser abreviado. Na verdade ele conseguiu abreviar até a narrativa. Assistimos à formação da short-story. ( $\mathrm{O}$ narrador», Abril, 1980, p. 63). «O cronista que narra os acontecimentos, sem distinguir entre os grandes e os pequenos, leve em conta a verdade de que nada do que um dia aconteceu pode ser considerado perdido para a história». («Sobre o conceito da história», Brasiliense, 1985, p. 223).

Amparando-me nessas lentes, coloco o caminho que estou procurando desenvolver no estudo do conto espanhol contemporâneo: a épica do fragmentário que ilumina a Espanha dos tempos modernos.

Vale lembrar que o conto começou a ampliar seu espaço de circulação durante o Sèculo XIX. Certamente que as condições de produção literaria têm aí papel decisivo, pois é o século, também na Espanha, da explosão da imprensa moderna, vale dizer, periódica e barata, dirigida especialmente aos pequenos ou grandes centros urbanos. Para esta imprensa - revistas ou jornais- escreviam Larra, Bécquer, Clarín. É a época dominada pelos contos de costumes, às vezes com pitadas de histórias extraordinárias. Fundamentalmente, a costrução do conto é feita por um narrador distanciado e personagens tipificados. É com o grupo de 98 que o conto começa a ganhar novos tons. Pensemos aqui no considerado narrador-nato dessa geração: Pío Baroja. A partir do ângulo realista, ele traz para o conto o cotidiano das pessoas comuns e a atmosfera melancólica transforma-se em tom dominante. Baroja ensaia as primeiras incursões ao universo psicológico da personagem, como em Águeda e El desconocido, histórias que conseguem recriar a frustração silenciosa da mulher perante seu massacrante dia-a-dia de reclusão e pequenas tarefas domésticas. Há histórias que discutem a perplexidade do homen perante a organização social, como em El carbonero, cuja personagem não pode compreender porque deva deixar sua aldeia para atender a uma convocação do exército. Mas Baroja ainda compõe histórias que se constituem em ver- 
dadeiros exempla, como Marichu, em que a ação desenvolvida pela personagem nasce de um conselho e a conduz a aceitar a convivência com a perda e a frustração porque esta é a situação a que estão submetidos todos os homens. Deve-se observa também que o centro do conto para Baroja é a ruptura da normalidade, é a situação excepcional ou diferenciada que irrompe no cotidiano. Por isso seus contos apoiam-se fundamentalmente no pilar da ação.

É na produção de pós-guerra que vemos o conto se abrir para a experimentação. Os poucos críticos que se dedicaram ao assumto (Eduardo Tijeras, Erna Brandenberg, Francisco García Pavón, Medardo Fraile) são unânimes em fazer esse corte. Há um grande grupo de narradores que se dedicam com mais vagar a procurar as possibilidades expressivas do conto. São autores que se formaran, que viveram sua juventude, sua época de descobertas em tempos de guerra: guerra civil espanhola e segunda guerra mundial. São homens cuja experiência está marcada pela forma mais radicalmente brutal de destruição. Camilo José Cela, Miguel Delibes, Ana María Matute, Rafael Sánchez Ferlosio e Carmen Martín Gaite compõen um grupo que produz paralelamente conto e romance, mas trabalham com igual rigor os dois gêneros. Até mesmo o prolixo Cela consegue momentos de condensação lírica (veja-se o conto «Catalinita» de Nuevo retablo de Don Cristobita); considere-se a diversidade de procedimentos narrativos dos contos de Delibes dos livros La mortaja e La partida; ou ainda a consciência de especificidade do gênero que revela Ana María Matute ao afirmar: «No conto cabe a intensidade, a capacidade de mistério da poesia»; ele «deve reunir três condições indispensáveis: ser breve, redondo e cheio de suco como uma laranja» (citado por E. Brandenberger, Estudios sobre el cuento español actual, Nacional, 1973, p. 40). Mas dentro desse grande grupo cabe destacar especialmente autores que, apesar de dedicarem-se tambén a outros gêneros, empenham-se na produção ou no estudo e na divulgação do conto. Nesse caso encontramos Aldecoa, García Pavón (org. da Antologia da Gredos, 1959), Jesús Fernández Santos (org. da Antología Taurus, 1975) e Medardo Fraile (contista e crítico). Há ainda que lembrar a produção literária e crítica de Francisco Ayala no exílio.

Acredito que toda essa produção seja importante para ajudar a compreender a Espanha contemporânea: acompanhá-la em sua entrada de sola e ao som de canhão no mundo irremediavelmente moderno, sem muralhas nacionais e sem ilusões de grandes missões civilizadoras a empreender. A diversidade de experiências e a impotência do homen em assimilá-las e compreendê-las está narrada de maneira eloquente na linguagem multifacetada do conto. Como rápido exemplo, tomemos Aldecoa que, com perspicácia, vê o conto como a captura do momentâneo, como cúmplice da percepção lírica. Diz Aldecoa: «O conto não se constrói com o ritmo dos acontecimentos. O conto se faz com o ritmo da palavra. O romance precisa ser construído; o conto se faz com a intuição» (Brandenberger, p. 139).

Com esta perspectiva, Aldecoa abriu diversas veredas para o conto, mergulhando na diversidade, nas contradições entre o moderno e o arcaico da vida espanhola contemporânea-dilaceramento típico dos países periféricos à riqueza do capitalismo central. Sua insistência em determinadas questões e ângulos fez com 
que a edição de seus contos completos fosse organizada por temas: as profissões, a classe média, o «basfons», o êxodo rural e a grande cidade, vidas estranhas, as crianças, a solidão dos velhos e a apatia dos homens acomodados. Estes títulos podem dar um esquadro dos caminhos do autor, mas, como toda classificação, esta tampouco consegue abranger a complexidade de problemas colocados pelos contos.

O conhecido texto Patio de armas, por exemplo, classificado no tópico «as crianças», é na verdade um exemplo da engenharia precisa e aparentemente simples de Aldecoa. O jogo das crianças na escola é o contraponto, na narração, ao jogo da guerra. O leitor experimenta, a partir da perspectiva da criança, a dificuldade em compreender as regras e o arbítrio do jogo, metáfora da violência sofrida pelo homem que não consegue compreender e conviver com as regras e o arbítrio da guerra da qual o prisioneiro não se salva. É um fragmento de narração do assunto que Aldecoa consegue criar com o mesmo impacto do título do contoPatio (escola) de armas. Creio que da linguagem contida, da agilidade de cenas e diálogos emerge a sensibilidade da guerra no cotidiano, de maneira bastante mais original que em outros contemporâneos que desenvolveram largamente o tema, como Pavón, por exemplo.

O mundo matizado e conturbado pelos sentimentos, visto por um narrador que adere à personagem e ao ambiente é o produto da habilidade de Aldecoa, que assim consegue perscrutar com densidade momentos de agudo estado de desgarramento das pessoas comuns na vida cotidiana. Outro conto exemplar, nesse sentido, é La nostalgia de Lorenza Ríos. Neste o autor recompõe, do ponto de vista social, o mundo arcaico dos homens ligados à pesca; revela seu modo de vida: o silenciar sobre conflictos pessoais, o tempo cíclico das classes que não têm vez no desenvolvimento do progresso, que se conforman com o lado atrasado da Espanha em que vivem e desconhecem o compasso moderno. Frases no balanço do mar, movimentos repetitivos das personagens e ausência de diálogo recriam o mundo regular das ondas e acenam para a imutabilidade da vida marginal e da solidão de cada um.

Aproximando-se uma vez e mais outra de diferentes aspectos particulares e concretos da terra espanhola e sua gente, Aldecoa supera a tradição do conto como caso, como exemplo, como o excepcional a ser contado e transforma o conto em ensaio de compreensão, em registro do momentâneo do cotidiano dos homens comuns, de qualquer homen, em qualquer hora. Esboça, assim, uma perspectiva moderna de épica: os descontínuos fragmentos da História do homen dilacerado dos «tempos modernos».

\section{BIBLIOGRAFÍA}

Tijeras, Eduardo. Últimos rumbos del cuento español. Buenos Aires, 1969. Brandenberger, Erma. Estudios sobre el cuento español actual. Madrid Ed. Nacional, 1973.

Fraile, Medardo: «Panorama del cuento comtemporáneo en España». Caravelle, n. 17 (1971). 